\title{
A PROPÓSITO DE LAS VÍCTIMAS: SER(ES) HUMANOS DESDE CUERPOS HUMANOS
}

\author{
Jairo Marcos* \\ doi: 10.11144/Javeriana.uph37-75.vshc
}

\section{RESUMEN}

La repolitización de los cuerpos por la que aboga este artículo defiende que los seres humanos no es que estén dotados de cuerpo, sino que son cuerpo. El ser humano es cuerpo viviente. Bajo esa problemática se plantea la cuestión acerca de las vidas que merecen la pena ser vividas, que hunde sus raíces en la pregunta por los cuerpos: ¿qué cuerpos sirven para devenir humanos? Para plantear la cuestión desde una filosofía transformadora y mediante un hilo decolonial, hay que partir de los cuerpos que sufren y hay que orientarse hacia futuros posibles donde la vida no sea el privilegio de unas corporalidades concretas. Dos posturas contemporáneas se abren paso en este debate vital: el feminismo cyborg (y su extremo, el transhumanismo) y el feminismo queer.

Palabras clave: humanidad; cuerpo; transhumanismo; cyborg; queer

\footnotetext{
Universidad Nacional de Educación a Distancia (UNED), España; Universidad Nacional Autónoma de México (unam), Ciudad de México, México.

Correo electrónico: jmarcos@desplazados.org

Para citar este artículo: Marcos, J. (2020). A propósito de las víctimas: ser(es) humanos desde cuerpos humanos. Universitas Philosophica, 37(75), 215-235. ISSN 0120-5323, ISSN en línea 23462426. doi: 10.11144/Javeriana.uph37-75.vshe
} 


\title{
ON THE VICTIMS: BEING HUMAN OUT FROM HUMAN BODIES
}

\begin{abstract}
To repoliticize the body is to assert that human beings do not have bodies, but they are bodies. The human being is a living body. This idea frames a fundamental ethical question- "which human lives are worth living?"-in different terms: "which bodies are apt or conformable to become human?". To address this question, which this article intends to, is to engage in transformative philosophy. Two contemporary currents of thought dive into this vital issue: cyborg feminism (and its extreme, transhumanism) and queer feminism. From a decolonial standpoint, a focus on the bodies that suffer and an orientation towards possible futures, where life might not be the privilege of some particular kinds of corporality, will prove fruitful to begin unraveling the answer.

Keywords: humanity; body; transhumanism; cyborg; queer
\end{abstract}




\section{Introducción.}

Los límites de la racionalidad para abordar lo humano

Migrantes, desplazadas, refugiados, solicitantes de asilo, sin papeles, polizones, vidas sobrantes, cuerpos que no importan, vidas dolientes. Generaciones pretéritas, presentes y virtuales. Seres humanos en el siglo XxI, aunque apenas unos pocos sirvan para el sistema: "no todo el mundo cuenta como sujeto. [...] Lo que está en juego es la existencia de unas comunidades no del todo reconocidas como tales, de unos sujetos que, estando vivos, no son considerados 'vidas"' (Butler, 2010, pp. 54-55).

¿Qué supone exactamente ser humanos? ¿La racionalidad es la puerta de entrada a dicha condición? ¿Acaso no son humanas todas las personas por el mero hecho de existir? ¿Hablamos de una característica per se del ser humano o de una reivindicación moral como proyecto político? ¿Y qué hay de los otros seres vivos? Por cierto, ¿en qué lugar posicionan a estos sujetos las fronteras entre el humano y la máquina? Para plantear estas cuestiones desde una filosofía transformadora, hay que partir de los cuerpos que sufren y hay que orientarse hacia futuros posibles donde la vida no sea el privilegio de unas corporalidades concretas. Dicho de otro modo, y tal como pretende este artículo, se trata de reubicar las transformaciones en y desde las víctimas.

No ha sucedido así hasta ahora. Encaramada en la ontología fundamental, la humanidad ha terminado diluida entre los engranajes de la totalidad y su procedimiento técnico-económico. Es la consumación lacerante de las víctimas: "a diario somos testigos de la deshumanización sistemática de las personas desechables" (Harvey, 2014, p. 292) ${ }^{1}$. Es la muerte de lo humano. La dificultad no es trivial, habida cuenta de que todas las sociedades son educadas con valores de existencia antes mercantiles que humanos, por lo que afrontar su deconstrucción provoca vértigo. ¿Podemos imaginar cosmovisiones de seres humanos, radicalmente humanos, en el siglo Xxi? Esta misma pregunta ya la han formulado otras voces, como es el caso del humanismo revolucionario de Franz Fanon (2014), quien desde una conciencia decolonial se pregunta si es posible (y cómo)

1 "We are daily witnessing the systematic dehumanisation of disposable people." Traducción del autor del artículo. 
restaurar la humanidad tras las prácticas deshumanizadoras protagonizadas por Occidente.

Entonces, repitiendo la pregunta: ¿existen seres humanos, radicalmente humanos, en el siglo xxI? No si entendemos lo humano como esencia inamovible y predeterminada, ni siquiera a partir de la racionalidad o logos. Pero sí como seres corporales, cuerpo como existencia, existencia como ser un cuerpo finito y vulnerable, vulnerabilidad histórica y abierta, apertura colectiva. Estas concepciones enfrentadas de lo humano son los dos límites entre los que discurre este artículo, que teje una perspectiva sobre la corporalidad tras la caída del paradigma biologicista, racionalista, especista e ilustrado, que desemboca en un diálogo crítico con el feminismo cyborg y con el feminismo queer.

La diferencia radica entre, por una parte, ser humano como categoría biológica y funcionalista, definido desde la ontología fundamental; y, por otra, tener (la posibilidad de) humanidad como asunción de una vocación de apertura a las víctimas ${ }^{2}$. Este segundo horizonte también parte del ser, pero del ser debilitado que participa en la transontología del otro como ámbito originario, es decir, un ser que no implica ya sustantivo alguno (ni fundamento ni esencia), sino un ser que se conjuga como verbo, fuente (en alemán, Quelle), como proceso en curso, acontecimiento, devenir de una ética intersubjetiva que parte del hecho de que, efectivamente, la humanidad tiene la posibilidad de ser más de lo que es, de vivir en acto toda su potencia, sin que ello suponga perfeccionamiento alguno, sino modos otros de vivir humanamente: "ha de explotar su potencial humano. [...] Su humanidad en potencia es muy superior a su humanidad en acto" (Küng, 2006, pp. 49-50)

2 Así lo expresa Gianni Vattimo: ser hombre "es una categoría que no proviene sino de la especie biológica y de una noción funcionalista de la cultura naturalizada, hasta el punto de no presentarse más que como nicho ecológico, por complejo que sea, de la especie, [mientras que tener humanidad] implica la asunción de un valor comunicacional centrado no en un hecho sino en una vocación" (Vattimo, 1992, p. 262). Más adelante, el filósofo italiano concreta el sentido de esa vocación: "tener humanidad es sentir lo común en lo diferente; aceptar lo distinto sin ceder a la repulsión del extraño” (p. 271).

3 Para activar el potencial humano, el teólogo Küng apuesta por compaginar el principio de responsabilidad de Jonas (1995) con el principio esperanza de Bloch (2007). 
El otro plural como a priori ético transformador recuerda la imposibilidad de alcanzar este "ser más humano" desde la pretendida autosuficiencia solipsista del yo abstracto y absoluto. Ni siquiera el logos racional, la razón excluyente que Occidente universaliza para fundamentar su ciencia, su técnica y su progreso, es el criterio definitorio y suficiente, pues las vergüenzas se agolpan desde las periferias: ¿y los recién nacidos?, ¿y las personas con diversidad psíquica?, ¿y quienes padecen trastornos mentales?, ¿acaso son excluyentes la lentitud intelectual o el olvido de quienes sufren Alzheimer? ¿Son menos humanos quienes sienten más de lo que razonan? Definir al ser humano desde una de sus dimensiones, la racional, sería tomar la parte por el todo, hacer de la cualidad racional el fundamento esencial de la humanidad.

\section{Lo humano como proximidad responsable con el otro plural}

UNA VEZ DESENMASCARADA la razón excluyente como fetiche que ordena ideológicamente la realidad, se hacen visibles los mitos que todavía hoy mantienen vivo al sistema. En demasiadas ocasiones la delimitación de lo racional conlleva exclusión, cuando no violencia, tal y como corrobora la imposición de la totalidad sobre sus alteridades: momentos en los que las mujeres no son consideradas racionales, en los que el progreso mantiene intacta su pretendida moralidad mientras convierte pieles negras en esclavos, en los que con justificaciones supremacistas se aboga por corregir el deterioro de la raza causado por la población judía; en suma, momentos en los que lo humano se define como oposición a las múltiples exclusiones en las que se refleja de forma inversa.

La humanización de ciertas categorías de personas (los hombres europeos) [...] se apoya dialécticamente en la naturalización de otras categorías de personas (las razas morenas y negras y las mujeres), a las que en adelante se definirá como salvajes, esto es, como seres puramente biológicos, carentes de razón, ética e historia, y cuya existencia está delimitada por los ciclos interminables de la reproducción biológica (Mies \& Shiva, 2014, p. 297).

Y es que la dignidad del ser humano no se fundamenta en la razón absoluta, sino que se realiza desde las exterioridades de ese otro plural: "la vida humana en comunidad es el modo de realidad del ser humano” (Dussel, 2001, p. 103), 
conjugada en el necesario cara-a-cara levinasiano ${ }^{4}$, que revela sin ambages la responsable codependencia de la humanidad: "nadie puede salvarse sin los otros. [...] Nadie puede quedarse en sí mismo: la humanidad [...] es una responsabilidad por los otros, una vulnerabilidad extrema” (Lévinas, 1974, p. 130). Una proximidad responsable que condensa la experiencia de vivir al servicio de las otras. "La condición humana se realiza en las relaciones. Por eso la dignidad del ser humano no es estática, sino [...] constantemente un vivo acontecer. La dignidad humana sucede" (Küng \& Rinn-Maurer, 2008, p. 43).

La humanidad es un momento intersubjetivo que surge desde el otro plural y que fecunda a quien se acerca. A partir de aquí, desde el momento en que lo moral conlleva necesariamente un enfrentamiento con la realidad injusta, la ética intersubjetiva se convierte en política. Es entonces cuando alcanzamos la dignidad de humanos, como consumación en el otro de la propia condición de seres humanos. La "búsqueda del ser más no puede realizarse en el aislamiento, en el individualismo, sino en la comunión, en la solidaridad de los que existen. [...] Nadie puede ser auténticamente prohibiendo que los otros sean. Esta es una exigencia radical" (Freire, 2012, p. 92).

La humanidad no solo es la condición más íntegra de los hombres, sino que también necesita el marco humano para conseguir manifestarse: los hombres se hacen humanos unos a otros y nadie puede darse la humanidad a sí mismo en soledad o [...] en el aislamiento. [...] Lo humanamente importante en el hombre $[\ldots]$ es $[\ldots]$ que se entiende con los demás hombres $y$, por tanto, [...] renuncia a utilizarlos y dominarlos (Savater, 1992, pp. 261-262).

Este descentramiento humano hacia las vidas sobrantes no abraza un especismo excluyente, pues los seres humanos solo son (posibles) como parte de la biodiversidad. Pero lo cierto es que, en ese horizonte ecosistémico, los seres humanos son, al menos en potencia y en función de situaciones concretas ${ }^{5}$, los únicos

4 La “inversión humana del en-sí y del para-sí, del 'cada cual para sí mismo' en un yo ético, en la prioridad del para-otro, [...] se produce en lo que llamamos 'encuentro con el rostro del otro’” (Lévinas, 1993, p. 250).

5 Los seres humanos "son porque están en situación. Y serán tanto más cuanto no solo piensen críticamente su estar, sino que críticamente actúen sobre él. Esta reflexión sobre la situacionalidad equivale a pensar la propia condición de existir" (Freire, 2012, p. 126). 
seres que pueden pre-ocuparse y servir conscientemente a los otros en el curso de su devenir. Por el contrario, los animales no-humanos son cerrados en sí mismos (no pueden separarse de su aquí-y-ahora ni de su sí-mismo de forma reflexiva) además de ahistóricos, "al no tener un mañana ni un hoy, por vivir un presente aplastante" (Freire, 2012, p. 111) ${ }^{6}$. Así, mientras el ser de los humanos es verbo, el ser de los animales es sustantivo, mundo físico, pero no histórico, realidad prefijada, lo que no les excluye ni de padecer sufrimientos ni de sentir dolor.

La vida humana así entendida no coincide plenamente con la supervivencia física, sino que refleja las posibilidades o modos de vivir del ser-acontecimiento abierto a las exterioridades: "no solo somos vivientes, sino que somos los únicos vivientes a los que la 'vida bumana' se nos ha dado 'a cargo'” (Dussel, 2001, p. 116). Es en este sentido que "la 'vida humana' no es un fin. Está más allá de toda teleología. [...] Es trans-teleológica, y es criterio de valorización" (Dussel, 2001, p. 117). La vida humana en comunidad es el hecho empírico de partida y su ausencia, demostrada en el cotidiano deambular de tantas periferias de vidas imposibilitadas, convierte su universalización, allá hasta donde sea posible, en el contenido mínimo exigible a todo pensamiento que se proponga pensar la realidad. Criterio de justicia histórico (político) y criterio de justicia material (corporal).

\section{Lo humano desde las corporalidades sufrientes}

No SE TRATA DE LA CORPORALIDAD que se fundamenta desde un ego cogito, pretendidamente neutra y objetiva, en el fondo fratricida de cuerpos otros ${ }^{7}$. La pluriversidad recupera la corporalidad viviente, lo que implica que el ser humano

6 En comparación, los seres humanos "pueden tridimensionalizar el tiempo (pasado-presentefuturo) que, con todo, no son departamentos estancos. Su historia, en función de sus mismas creaciones, va desarrollándose en constante devenir, en el cual se concretan sus unidades epocales" (Freire, 2012, p. 115).

7 El ego cogito impone su ontología fundamental mediante la destrucción de los cuerpos de ese otro plural y radicalmente necesario como a priori ético para un planteamiento transformador. No reconocer este hecho es posicionarse a favor de un asesinato de la alteridad que, a la postre, resulta ser un suicidio colectivo: "el rostro del otro implora: no me mates. Al no hacerlo, no se salva solamente al otro; uno también se salva a sí mismo” (Hinkelammert, 1998, p. 315). 
no vive en abstracto, entre las líneas teóricas de argumentos, sino aquí-y-ahora, tiene hambre y siente sed, necesita abrigo y cuidados, goza la experiencia estética de las artes y el relajo del ocio, se empodera con las letras y la fe. Es desde ese soporte material que las personas viven humanamente. La antropología transmoderna (Dussel, 2009) de la sensibilidad tiene como criterio último el "tuve hambre y me disteis de comer", con el hambre como metáfora de un momento real de corporalidad negada, de humanidad sufriente, y con el dar de comer como acto críticamente consciente. El ser humano es cuerpo viviente.

Fruto de personas, lugares y tiempos con nombres y apellidos, toda filosofía o saber es contextual y por ende situado; esta es una de las autoconciencias claves del giro decolonial, que sitúa las raíces del ego cogito, ergo sum (yo pienso, luego existo) cartesiano en el ego conquiro, ergo sum (yo conquisto -aniquilo, violo, robo y un largo etcétera-, luego existo), y de ahí da el salto hasta el "soy donde pienso". Es una parcialidad consciente puesta precisamente al servicio de las víctimas. La filosofía sale reforzada con esta concienciación de su punto de partida, de su horizonte de formulación, de su localización. De ahí que estos párrafos sigan un hilo decolonial.

Soporte material de cualidades y vivencias ${ }^{8}$, los cuerpos, en concreto los periféricos, son cotidianamente negados por el sistema a través de la alienación del trabajo vivo (Marx 2000)9 , de la represión pulsional (Freud, 2009) ${ }^{10}$, de la

8 El término "sujeto" proviene de la raíz latina subjectum, lo que está debajo y permanece como sustrato, habida cuenta de que ni las cualidades ni las experiencias pueden darse sobre la nada. Es la inextricable unión de cuerpo y alma, materia y espíritu. De forma paralela a la postergación sufrida por el cuerpo, la expresión "sujeto" evolucionó filosóficamente, hasta acercar el subjectum al sujeto activo y absoluto, encarnado en el ego cogito (yo pienso) cartesiano, el Ich denke (yo pienso) kantiano o el Ich arbeite (yo trabajo) marxiano.

9 Marx reflexiona en torno a la alienación desde la vida humana negada, desde la alienación y deshumanización del trabajador que deposita su vida en el producto del capital sin posibilidad de recuperarla. La necesaria existencia de los cuidados de ese trabajador, humanamente en situación de dependencia (de nutrición, abrigo o afecto), bajo la óptica marxiana no genera valor alguno para la maquinaria del capitalismo, cuya única víctima originaria sería la del trabajador atado a su engranaje de beneficios.

10 Freud reflexiona en torno a lo reprimido del inconsciente; su "super-yo" represor aliena las pulsiones de la estructura libidinal de tal forma que toda "liberación sería fanatismo o fideísmo. Para las 
disciplina moderna (Foucault, 2002) ${ }^{11}$, de la performatividad del género (Butler, 2002). "El resurgimiento de la problemática del sujeto, de la subjetividad subyacente y de la corporalidad, última instancia material y viviente humana, aparece más claramente cuando se postula como la 'afirmación' de una dignidad absoluta 'negada' por el sistema” (Dussel, 2001, p. 340). La corporalidad es una esfera clave en las relaciones de poder establecidas por la totalidad dominante en menoscabo de las exterioridades dominadas. La filosofía moderna termina degradando el cuerpo a mera carne (la res extensa cartesiana), lo que acarrea la abstracción del dolor y el sufrimiento humanos. Una degradación de la que han sido partícipes las religiones: "Por un lado, llevaron al extremo la repulsa por la carne como lugar de placer, siempre asociada al sexo y a las mujeres. Por otro, incitaron a los creyentes a asistir a los cuerpos de sus prójimos sin otra mediación más allá de la compasión" (Santos, 2014, p. 116).

La repolitización de los cuerpos parte precisamente de la consideración de que los seres humanos no es que estén dotados de cuerpo, sino que son cuerpo: "no tenemos, sino que somos cuerpo, [...] no solo individualmente, sino colectivamente" (Cerutti, 2005, pp. 466-467). Cuerpos jóvenes, cuerpos negros, cuerpos atléticos, cuerpos ancianos, cuerpos blancos, cuerpos transexuales, cuerpos europeos, cuerpos de mujer, cuerpos activos, cuerpos indígenas, cuerpos pensantes, cuerpos colonizados, cuerpos de hombre, cuerpos enfermos, cuerpos morenos, cuerpos alienados, cuerpos descansados, cuerpos sanos... ¿Qué cuerpos importan y por qué? ¿Cuáles merecen la pena ser vividos? ¿Todos son llorados? Cada uno de estos cuerpos configura, de forma no excluyente, inclusiones y exclusiones humanas que urgen ser pensadas.

La repolitización de los cuerpos radica en la aceptación de su vulnerabilidad, finitud y precariedad respecto a su contexto histórico-social y lingüístico, admitiendo la interdependencia y exposición activa de unos cuerpos con otros:

víctimas [...] el horizonte teórico freudiano se cierra al final sin esperanza y sin alternativa" (Dussel, 2009, p. 356).

11 Foucault reflexiona en torno a los cuerpos disciplinados por las instituciones modernas, excluyendo de su análisis, como si no existieran, los cuerpos colonizados. 
El cuerpo no es una realidad dada previamente, de naturaleza incontestable, aislada e independiente del orden social: es más una relación que una entidad. El cuerpo se conforma con otros cuerpos, en una atmósfera espacial y temporal que fluye, deviene; [...] pero no de un modo pasivo y sumiso, porque el cuerpo a la vez actúa y en su acción modifica, desplaza las normas que le dan cobijo (Burgos, 2016, p. 619).

\section{Lo humano transontológico}

Es ASí QUE LOS CUERPos no son meramente ontológicos, sino transontológicos, éticos, meta-físicos (más allá de la física), toda vez que están a merced de $\operatorname{otros}^{12}$. La vulnerabilidad material (económica), política (género-sexual) e inmaterial (ocio-espiritual) de la humanidad recuerda que los seres humanos son a merced de otros. Ser cuerpo es no poder vivir de espaldas al otro como a priori ético transformador:

Los cuerpos no pueden "ser" pensados sin su finitud y dependen de lo que hay fuera de sí mismos para sostenerse, unos rasgos que pertenecen a la estructura fenomenológica de la vida corporal. Vivir es siempre vivir una vida que se halla en peligro desde el principio y que puede ser puesta en peligro o eliminada de repente desde el exterior y por razones que no siempre están bajo el control de uno (Butler, 2010, p. 52).

Una posición que, a la postre, desnuda aquellos cuerpos que no importan, las vidas sobrantes que no merecen la pena ser vividas ni lloradas. Así sucede actualmente cuando se sostienen las igualdades y las desigualdades sociales en los propios cuerpos atomizados:

12 La única forma de mantener la ontología como el plano en el que se mueven los cuerpos es mediante expresiones lingüísticas como la de Butler (2010), quien habla de "ontología social": "hablar de 'ontología' a este respecto no es reivindicar una descripción de estructuras fundamentales del ser. [...] El 'ser' del cuerpo al que se refiere esta ontología es un ser que siempre está entregado a otros; a normas, a organizaciones sociales y políticas que se han desarrollado históricamente con el fin de maximizar la precariedad para unos y minimizarla para otros. No es posible definir primero la ontología del cuerpo y referirnos después a las significaciones sociales que asume el cuerpo" (p. 15). 
Los desposeídos y dependientes no lo son porque se les haya negado el acceso a la riqueza social, sino porque no tienen capacidades físicas, intelectuales o morales para conseguirla. [...] Lo anatómico-fisiológico ocupa un lugar central. El resultado es que la exclusión social queda naturalizada, ya que la situación de excluido se asocia con una característica física (Izquierdo, 1998, pp. 61-62).

Las posibilidades e imposibilidades de ser humanos se justifican en los cuerpos individualizados. Solo unos cuerpos privilegiados parecen merecedores de humanidad. Y, sobre todo, las diferencias de género se sostienen sobre términos orgánicos ahistóricos, sobre diferencias corporales (entre ellas, las sexuales) naturalizadas. Concebidas como lo otro de lo mismo (el hombre privilegiado), las mujeres aparecen ante la totalidad como destinadas a convertirse en la mujer singular "encadenada a su fisiología, volviéndose prisionera de su útero" (Arruzza, 2010 , p. 94). La base material del cuerpo-sexo es utilizada como pista de aterrizaje de construcciones sociales posteriormente naturalizadas. "No se nace mujer: se llega a serlo" (Beauvoir, 2000, p. 109).

La paradoja que encierra el cuerpo social que somos reside en el hecho de ser por una parte materia biológica y por otra, producto social. Por un lado, organismo empírico, suma de partes orgánicas, la visión a la que se aferra la ciencia occidental, y por otro, devenir identitario sobre el que actúan constitutivamente los mecanismos del poder, análisis que privilegian el psicoanálisis y la sociología desde sus respectivos campos. Una perspectiva decolonial desde las periferias visibiliza de partida las estructuras de poder heredadas por la posmodernidad. No desde una modernidad incompleta, que se lame las heridas de su barbarie, sino desde las múltiples periferias que se asoman por todas aquellas ventanas abiertas por la herencia moderna, sin perder de vista las puertas tapiadas por su razón excluyente.

El reto reside precisamente en conjugar los diferentes campos de acción, el material, el político y el inmaterial. Pensar desde las víctimas como instancia decisiva no implica negar las particularidades biológicas de los cuerpos, sino posicionarse frente a sus jerarquías y exclusiones, es decir, exige "no resistir la vulnerabilidad, sino resistir desde la vulnerabilidad” (Burgos, 2016, p. 619); tampoco implica resignarse a la alienación identitaria de la totalidad dominante, sino buscar las grietas transformadoras, es decir, exige "desbaratar la presión coercitiva 
que las normas de género, sexo, sexualidad, y las instituciones que las sostienen y reproducen, ejercen sobre nuestras vidas" (Burgos, 2016, p. 619). Se trata de esquivar el esencialismo, evitando al mismo tiempo los determinismos biológico y constructivista.

Esta postura complejiza sobremanera la cuestión de los sujetos en sus respectivos campos de acción. Sin ir más lejos, el referente "mujer", sujeto plural de las políticas de liberación de la mitad de la humanidad, se revela "construido a través de una multiplicidad de discursos, posiciones y significantes que a menudo entran en conflicto entre sí; por tanto, el significante mujer ya no constituye una piedra fundacional del proyecto feminista" (Braidotti, 2000, p. 123). En otras palabras, la etnia, el origen, la edad, el color de piel, la preferencia sexual, el hábitat, el estilo de vida, el patrimonio y la preferencia religiosa, entre otras experiencias, atraviesan la identidad de las mujeres. $\mathrm{O}$, dicho de otra forma: "no existe nada en el hecho de ser 'mujer' que una de manera natural a las mujeres. No existe incluso el estado de 'ser' mujer que, en sí mismo, es una categoría enormemente compleja construida dentro de contestados discursos científicosexuales y de otras prácticas sociales" (Haraway, 1995, p. 264). El sujeto "mujer", incluso pluralizado en "mujeres", pierde el papel central que juega en los feminismos contemporáneos mayoritarios; se debilita para abrir campo a otro tipo de liberaciones humanas. Así, cuando estas líneas identifican a la mitad de la humanidad como una de las exterioridades decisivas en cuanto víctimas de la totalidad, el sujeto "mujeres" apunta más a un sujeto-siendo que a un sujeto-sido, a un proceso abierto que a una esencia concreta. Y lo mismo sucede con otras identidades individuales y colectivas negadas como víctimas, cuya subjetividad se debilita, obligando a partir de entonces a aplicar una hermenéutica en permanente revisión de sus contornos.

El desafío del cuerpo social que somos conduce a una subversión de los valores que ya persiguió la transvaloración nietzscheana (Umwertung der Werte, Nietzsche, 1972) sin superar la dualidad transversal hombre-mujer, ya que las cualidades definitorias del superhombre (Übermensch), como la fuerza y la nobleza, quedaban reservadas para el primer término del binomio. La urgencia de fondo llega hasta la actualidad: ¿Qué vidas son las que merecen la pena ser vividas? Dilema bajo el que subyace la pregunta por los cuerpos: ¿qué cuerpos sirven para devenir humanos? 
La persona se proyecta como un valor universal que trasciende el espacio y el tiempo; pero su carnalidad es por excelencia la cuestión cotidiana, la vida del aquí-y-el-ahora. La abstracción de la persona, su ubicación en el no-lugar y notiempo, rezuma imposible dados unos cuerpos finitos y vulnerables, históricos, abiertos y colectivos. Y puesto que el suelo de proyección humana es plural, distinto, injusto para las víctimas, "las aspiraciones de unos chocan con las de los otros, y siempre los débiles -que son la mayoría- deben renunciar a sus aspiraciones" (González, 1978, p. 130), a su dignidad e incluso a sus corporalidades ${ }^{13}$. La filosofía transformada parte de los cuerpos que sufren, y se orienta hacia futuros posibles donde la vida no sea el privilegio de unas corporalidades concretas. Dos posturas contemporáneas se abren paso en este debate vital, ambas posicionándose entre la extrema complejidad que supone la deconstrucción y transformación de las subjetividades corporales, incluyendo la del significante "mujer": el feminismo cyborg (y su extremo, el transhumanismo) y el feminismo queer.

\section{Lo humano y la descorporalización cyborg}

LAS DOS CORRIENTES trabajan con subjetividades históricas y abiertas, con las categorías del género y el sexo a vueltas, pero yendo más allá, como en una despedida soñada a las construcciones de género: "el género, después de todo, podría no ser la identidad global, incluso si tiene anchura y calado histórico" (Haraway, 1995, p. 309 ${ }^{14}$. Como transontologías, plantean una superación genéricosexual de la ontología fundamental, desafían al ser fundamento de la totalidad, respectivamente, desde el otro-máquina y desde el otro-performatividad. Se

13 Así ocurre con las corporalidades que no encajan en las normas y medidas impuestas, caso de los cuerpos infecciosos, los cuerpos mutilados o los cuerpos gruesos. Diferentes corrientes reivindican estas corporalidades disidentes y disruptivas: "estamos empezando a hablar desde nuestras propias carnes [...]: las que sobran, las que faltan, las que están viejas, las que están enfermas, las que no son funcionales. Es necesario empezar a cuestionarnos cómo se crea el cuerpo normal y evidenciar su carácter de artefacto. Nuestros cuerpos gordos, enfermos, viejos o discapacitados son construcciones sociales. [...] Así definidos, son el resultado de relaciones sociales donde unos cuerpos se privilegian sobre otros" (Masson, 2014, p. 226).

14 Que el género deje de ser la identidad global no resta importancia a los cuerpos dolientes y finitos, que continúan siendo pantallas activas en las que fluyen e influyen las identidades y las estructuras de poder. 
fusionan las fronteras identitarias, fluyen los límites hasta ahora fijos y esenciales de lo humano, dejan de ser útiles las relaciones dialécticas entre pares de valores binarios masculino-femeninos para analizar la sociedad. Ambas comparten y prometen una esperanzadora liberación de los seres humanos, pero desde definiciones antagónicas de lo que representan lo humano y sus cuerpos. El yo y el otro están nuevamente sobre el tablero, si es que alguna vez lo abandonaron, aunque se pretende su transubstantivación: "en cualquier caso, el esquema yo-otro, al amparo de cuya dialéctica se construye el sujeto, queda subvertido" (Aguilar, 2008, p. 112).

Lo cyborg, representado por autoras como Donna Haraway, pierde el miedo a las hibridaciones viviente-máquina y borra el binarismo de género y su dualidad de valores hombre/mujer, cultura/naturaleza, mente/cuerpo, incluso humano/robot. Desde pretensiones eugenésicas ${ }^{15}$, sustituye (pero no elimina) la necesidad de un sujeto colectivo revolucionario: la acción o responsabilidad ya no recae en las mujeres, como pretenden otros feminismos, ni en la clase obrera, como defiende el marxismo, sino en figuras cruzadas ${ }^{16}$ compuestas por cuerpo y máquina, más allá de los géneros; de ahí su lema: "prefiero ser un cyborg que una diosa”. Su apuesta bosqueja un cuerpo desnaturalizado que, en su forma más extrema, es leído como obstáculo y queda eliminado: el transhumanismo prescinde por completo del soma, proponiendo la transferencia (transbiomorfosis) de la conciencia humana a la memoria de un ordenador: "El mundo puede ser leído como un problema de códigos, pura información, y el sistema biótico que es el individuo, como un componente más del sistema" (Aguilar, 2008, p. 14). Es el planteamiento por la existencia de una mente no encarnada en un cuerpo, el camino hacia la "inmortalidad, [...] una vida eterna sin encarnación temporal, pura esencia” (Aguilar, 2008, p. 71).

15 La eugenesia es una filosofía social que propugna el perfeccionamiento de la especie humana mediante la intervención selectiva en los rasgos hereditarios. Sus raíces se hunden en el darwinismo social de pensadores como Herbert Spencer y su máxima de la "supervivencia del más apto".

16 "El modelo del cyborg implica una visión del cuerpo que no es ni física, ni mecánica, ni meramente textual. [...] Funciona más bien como un contraparadigma de la intersección corporal con la realidad externa" (Braidotti, 2000, p. 128). 
Esta utopía contemporánea ${ }^{17}$ lanza su órdago por la racionalidad y la tecnología, en aras de trazar el ideal del perfeccionamiento humano ${ }^{18}$, siguiendo así la encomienda recibida de la Ilustración ${ }^{19}$. Es la recaída en el ser abstracto disponible y dispuesto para su divinización creadora. Lo cyborg denuncia la complicidad de la razón excluyente con la totalidad, pero considera poder hacer uso de dicha racionalidad tecnológica para invertir el orden de la dominación de la técnica sobre su humanidad; la alianza cuerpo-máquina no sería alienante, sino satisfactoriamente humanizadora para esta transontología, pasando por encima de las advertencias vertidas por Heidegger (2009) y Habermas (1986) respecto a la técnica moderna y la ideología. La simbiosis cuerpo-máquina imagina "un mundo sin géneros, sin génesis y, quizás, sin fin. (...) El cyborg es una criatura en un mundo postgenérico" (Haraway, 1995, pp. 254-255). El ser ¿humano? se despoja de su finitud: "la muerte no es inevitable. La muerte puede ser derrotada. Este es el lema principal” (Diéguez, 2017, p. 22).

Pero sucede que esta liberación, a base de romper sin miedo las barreras entre lo animal y lo humano, de destrozar sin pudor las fronteras entre lo vivo y lo inerte, de aniquilar sin temor las distinciones entre lo material y lo inmaterial, no se traduce en una liberación de las víctimas, sino que se queda en una liberación imposible de sus cuerpos en tanto que la humanidad no tiene sino que es cuerpo social y, como tal, su transformación liberadora no es posible desanclándose de

17 Algunas voces la consideran la aventura contemporánea por excelencia, el único gran relato posible tras la caída de cualquier otro gran relato posible.

18 "Prevemos la viabilidad de mejorar el potencial humano, superando el envejecimiento, las limitaciones cognitivas, el sufrimiento involuntario y nuestro confinamiento al planeta Tierra" [ We envision the possibility of broadening human potential by overcoming aging, cognitive shortcomings, involuntary suffering, and our confinement to planet Earth."] (Humanity+ Board, 2009). Traducción del autor del artículo.

19 El ser humano ha recibido el diagnóstico de "mejorable" repetidas veces, y tradicionalmente sus limitaciones se han tratado con recetas como la educación, las leyes o los hábitos. "Lo novedoso es que ha crecido la impaciencia con la lentitud y las limitaciones de los procedimientos tradicionales [...] y algunos han decretado su simple fracaso. Han surgido voces diversas que sostienen [...] que ha llegado la hora de dejar que sean las tecnologías biomédicas o incluso las cibernéticas las que tomen el asunto de la mejora humana en sus manos, efectuando transformaciones mediante la intervención directa e interna en los individuos" (Diéguez, 2017, pp. 31-32). 
estos, sino en la celebración de su interdependencia finita y vulnerable, histórica, abierta y colectiva.

Incluso en el caso de que todas las víctimas, Sures de geografía diversa, mujeres y vidas sobrantes, tuvieran acceso a la hibridación cuerpo-máquina, cuestión que obvian las políticas cyborg callando el locus enuntiationis de la técnica junto a lo $\mathrm{mismo}^{20}$; incluso si fuera posible una dominación airosa del determinismo tecnológico, aun pasando por encima de la ideología consumista y cosificadora que implica construir cuerpos a demanda; incluso si fuera posible la liberación del otro plural desde la acción en los cuerpos aislados ${ }^{21}$, pretensión de mejora del todo (la sociedad) mediante la suma agregada de partes (los individuos); no se trata de liberarse de la condición humana, sino, antes al contrario, de ser humanos, el revolucionario anhelo freireano de ser más, lo cual solo es posible desde los cuerpos. No se trata de ser antihumano, pero tampoco poshumano, hasta superar la finitud y la vulnerabilidad. Y es que, una vez más, no se trata de "resistir la vulnerabilidad, sino resistir desde la vulnerabilidad" (Burgos, 2016, p. 619).

\section{La precariedad queer}

EL FEMINISMO 2UEER, representado por filósofas como Judith Butler, regresa precisamente a los cuerpos vulnerables, en su caso, a través de la metamorfosis que desgenerifica hasta el punto de que el otro ya no es "solo" la mujer, sino muchos otros: "la dinámica yo-otro que inaugura el juego de la diferencia [...] es también objeto de deconstrucción: yo soy otro, otro soy yo" (Aguilar, 2008, p. 112). Se trata de un regreso a la materia corporal, "no como sitio o superficie, sino como un proceso de materialización que se estabiliza a través el tiempo para producir el efecto de frontera, de permanencia y de superficie" (Butler, 2002, p. 28).

20 Quienes, dentro del transhumanismo, admiten la posibilidad de que la mejora antropotécnica introduzca una mayor desigualdad social, dado su diferente acceso entre clases sociales, argumentan que la exclusión de algunos grupos es temporal y, en todo caso, no es razón suficiente para censurar las mejoras.

21 "El transhumanismo comparte con el neoliberalismo una gran confianza en la capacidad autoconformadora y transformadora del individuo, pero parece compartir también su despreocupación por la cuestión social" (Diéguez, 2017, p. 158). 
El género y el sexo no son transformaciones prefijadas de una vez por todas, sino repeticiones (performatividades) que estabilizan y desestabilizan los cuerpos, momentos que sedimentan y disciplinan la construcción sexo-genérica identitaria, junto a coyunturas que posibilitan su deconstrucción y posterior subversión.

En este proceso reiterativo, no es el sexo el que determina el género, sino que la relación causa-efecto se invierte y es el género, modelado por las relaciones de poder de un esquema heteropatriarcal, el que conforma el cuerpo-sexo ${ }^{22}$. Ya no importa tanto lo que habita entre las piernas, sino el discurso performativo y los ideales regulatorios:

La diferencia sexual nunca es sencillamente una función de diferencias materiales que no estén de algún modo marcadas y formadas por las prácticas discursivas. [...] El "sexo" no solo funciona como norma, sino que además es parte de una práctica reguladora que produce los cuerpos que gobierna. [...] En otras palabras, el "sexo" es una construcción ideal que se materializa obligatoriamente a través del tiempo (Butler, 2002, pp. 17-18).

La materialización humana nunca es para siempre, así que el cuerpo y el sexo no son identidades estáticas, sino las relaciones dinámicas entre ejes de poder que delimitan aquellos cuerpos que ameritan ser llorados, aquellas vidas que merecen la pena ser vividas. Entre las zonas humanas y las áreas salvajes se producen fuerzas de inclusión y exclusión que definen, separándolas, las esferas del yo-nosotros y del ellas-ellos/otras-otros. Esta delimitación de los seres humanos se construye a partir del reflejo inverso de lo mismo en las víctimas, o sea, sin poder obviar a ese otro plural como a priori ético: "el sujeto se constituye a través de la fuerza de la exclusión y la abyección, una fuerza que produce un exterior constitutivo del sujeto, un exterior abyecto que, después de todo, es 'interior' al sujeto como su propio repudio fundacional” (Butler, 2002, p. 20).

Es en ese ámbito transontológico, en ese exterior interno, en donde se posibilita, más allá del esencialismo y del constructivismo, el reto pendiente de la deconstrucción y transformación de los seres y los cuerpos humanos, incluido

22 'La diferencia sexual no es lo mismo que las categorías de 'mujer' y 'hombre'. Mujer y hombre existen [...] como normas sociales y son, de acuerdo con la perspectiva de la diferencia sexual, formas en las que la diferencia sexual ha asumido un contenido" (Butler, 2006, pp. 296-297). 
el referente "mujeres", a estas alturas ya debilitado ${ }^{23}$, lo que no obliga a que deje de pronunciarse como grito liberador: "uno habla como mujer con el propósito de dar mayor fuerza a las mujeres, de activar cambios sociosimbólicos en su condición: esta es una posición radicalmente antiesencialista" (Braidotti, 2000, p. 30). La deconstrucción del sujeto revolucionario "mujeres" no anula su potencial, sino que abre su alcance a alteridades que el feminismo del Norte no puede colonizar ni liderar. Una transformación del ser humano que estará siempre incompleta, habida cuenta del carácter verbal, procesual, del ser.

\section{Conclusiones para seguir tejiendo humanidad}

EL SER hUMANo es cuerpo viviente. Tal y como se ha subrayado hasta aquí, existen seres humanos, radicalmente humanos, siempre y cuando se parta de esa corporalidad existencial de unos seres finitos y vulnerables, históricos, abiertos y colectivos. Se trata, no hay que perderlo de vista, de una repolitización de los cuerpos que destaca precisamente no el tener sino el ser cuerpo de la humanidad. Una repolitización que, a su vez, configura o da forma a la transontología del otro como ámbito originario, a un ser en proceso, fuente y no fundamento. Imposible abrazar a esa humanidad en curso sin desatarse de la autosuficiencia del ego cogito.

La humanidad se revela entonces como un momento intersubjetivo que surge desde el otro plural y que fecunda a quien se acerca, lo que devela a su vez que no hay ser humano en abstracto, sino encarnado en un soporte material, tanto en su dimensión social como individual. El ser humano es cuerpo viviente, corporalidad necesariamente finita, vulnerable y precaria. Porque los seres humanos son a merced de otros, posición de vulnerabilidad que revela con toda su crudeza todas esas vidas que ni son lloradas ni son dignamente vividas.

El otro plural aparece como ser humano y exige justicia desde las periferias. Es un otro mayoritario aunque oprimido, y negarlo es excluir a la mayoría de

23 'No es preciso que exista un 'agente detrás de la acción', sino que el 'agente' se construye de manera variable en la acción y a través de ella. Esto no supone regresar a una teoría existencial del yo conformado por medio de sus actos, porque la teoría existencial confirma una estructura prediscursiva tanto para el yo como para sus actos. Lo que [...] interesa [...] es [...] la construcción discursivamente variable de cada uno en el otro y a través de él" (Butler, 2017, pp. 277-278). 
la humanidad que somos todos. No somos, no podemos ser, sin los otros. Bajo ese horizonte transformador, las víctimas, cuyos cuerpos repolitizados dejan de ser entes abstractos, exigen justicia, reclamando no solo el cumplimiento de los derechos vigentes, sino otra comunidad posible históricamente. Como instancias decisivas, son las víctimas las que exigen el debilitamiento de la totalidad y liberarse de sus ataduras.

La transformación es posible a partir de los cuerpos sufrientes, en una corporalidad (nuevamente individual y social) abierta, que rehúye los privilegios de unos pocos cuerpos. El feminismo cyborg y el feminismo queer abordan esos horizontes, desde una preocupación compartida pero con prescripciones muy dispares. Mientras la tecnificación corporal de lo cyborg promete la perfección humana y la definitiva superación de su finitud, recayendo así en el ser abstracto que pretendía superar, el énfasis en la vulnerabilidad corporal del feminismo queer enfatiza la dimensión corporal de la humanidad como proceso, como un juego de relaciones dinámicas que posibilita el grito liberador de la humanidad sufriente.

\section{Referencias}

Aguilar, T. (2008). Ontología cyborg: el cuerpo en la nueva sociedad tecnológica. Barcelona: Gedisa.

Arruzza, C. (2010). Las sin parte. Matrimonios y divorcios entre feminismo y marxismo. (Trad. A. Coll). Madrid: Izquierda Anticapitalista.

Beauvoir, S. (1949/2000). El segundo sexo. (Trad. A. Martorell). Madrid: Cátedra.

Bloch, E. (1959/2004-2007). El principio esperanza (trad. F. González) (Ed. F. Serra). I, II, III Vol. Madrid: Trotta.

Braidotti, R. (1994/2000). Sujetos nómades: corporarización y diferencia sexual en la teoría feminista contemporánea. (Trad. A. N. Bixio). Buenos Aires: Paidós.

Burgos, E. (2016). Cuerpos feministas en revolución. Daimon. Revista Internacional de Filosofía, 5, 611-620.

Butler, J. (1993/2002). Cuerpos que importan: sobre los limites materiales y discursivos del sexo. (Trad. A. N. Bixio). Lanús: Paidós. 
Butler, J. (2004/2006). La cuestión de la transformación social. En: Deshacer el género (pp. 289-327). (Trad. P. Soley-Beltrán). Barcelona: Paidós.

Butler, J. (2009/2010). Marcos de guerra: las vidas lloradas. (Trad. B. Moreno). Ciudad de México: Paidós. Butler, J. (1999/2017). El género en disputa: el feminismo y la subversión de la identidad. (Trad. M. A. Muñoz). Madrid: Paidós.

Cerutti, H. (2005). Preliminares hacía una recuperación del cuerpo en el pensamiento latinoamericano contemporáneo. Realidad. Revista de Ciencias Sociales y Humanidades, 105, 461-480.

Diéguez, A. (2017). Transhumanismo: la búsqueda tecnológica del mejoramiento humano. Barcelona: Herder.

Dussel, E. (2001). Hacia una filosofía política crítica. Bilbao: Desclée de Brouwer. Dussel, E. (1998/2009). Ética de la liberación en la edad de la globalización y la exclusión. Madrid: Trotta.

Fanon, F. (1961/2014). Los condenados de la Tierra. (Trad. J. Campos). México D. F.: Fondo de Cultura Económica.

Foucault, M. (1975/2002). Vigilar y castigar: nacimiento de la prisión (trad. A. Garzón). Buenos Aires: Siglo XXI.

Freire, P. (1968/2012). Pedagogía del oprimido. (Trad. J. Mellado). Madrid: Siglo XXI.

Freud, S. (1966/2009). El malestar en la cultura y otros ensayos. (Trad. R. Rey). Madrid: Alianza.

González, L. J. (1978). Ética latinoamericana. Bogotá: Universidad Santo Tomás.

Habermas, J. (1968/1986). Ciencia y técnica como 'ideología' (trad. M. Jiménez). Madrid: Tecnos.

Haraway, D. J. (1991/1995). Manifiesto para cyborgs: ciencia, tecnología y feminismo socialista a finales del siglo xx. En: Ciencia, cyborgs y mujeres: la reinvención de la naturaleza (pp. 251-311). (Trad. M. Talens). Madrid: Cátedra.

Harvey, D. (2014). Seventeen Contradictions and the End of Capitalism. Londres: Profile Books.

Heidegger, M. (1927/2009). Ser y tiempo. (Trads. M. Garrido, J. L. Molinuevo y F. Duque). Madrid: Tecnos. 
Hinkelammert, F. J. (1998). Asesinato es suicidio: cortar la rama del árbol en la cual se está sentado. En: El grito del sujeto: Del teatro-mundo del evangelio de Juan al perro-mundo de la globalización (pp. 287-320). (Trads. E. Tamez \& P. Richard). San José: Departamento Ecuménico de Investigaciones.

Humanity+ Board. (2009). Transhumanist Declaration. Recuperado de: https://humanityplus.org/philosophy/transhumanist-declaration/.

Izquierdo, M. J. (1998). El malestar en la desigualdad. Madrid: Cátedra.

Jonas, H. (1988/1995). El principio de responsabilidad: ensayo de una ética para la civilización tecnológica. (Trad. J. M. Fernández). Barcelona: Herder.

Küng, H. (1990/2006). Proyecto de una ética mundial. (Trad. G. Canal). Madrid: Trotta.

Küng, H., \& Rinn-Maurer, A. (2005/2008). La ética mundial entendida desde el cristianismo. (Trad. C. Martín). Madrid: Trotta.

Lévinas, E. (1972/1974). El extrañamiento en el ser. En: Humanismo del otro hombre (pp. 127-133). (Trad. D. E. Guillot). Naucalpan de Juárez: Siglo Veintiuno.

Lévinas, E. (1991/1993). Entre nosotros: ensayos para pensar en otro. (Trad. J. L. Pardo). Valencia: Pre-Textos.

Marx, K. (1867/2000). El capital: crítica de la economía política. (Trad. V. Romano). Madrid: Akal.

Masson, L. (2013/2014). Un rugido de rumiantes. Apuntes sobre disidencia corporal desde el activismo gordo. En: M. Solá \& E. Urko (Eds.), Transfeminismos: Epistemes, fricciones y fujos (pp. 225-233). Tafalla: Txalaparta.

Mies, M., \& Shiva, V. (1993/2014). Ecofeminismo: teoría, crítica y perspectivas. (Trads. M. Bofill et al.). Barcelona: Icaria.

Nietzsche, F. W. (1887/1972). La genealogía de la moral: un escrito polémico. (Trad. A. Sánchez). Madrid: Alianza.

Santos, B. (2014). Se Deus fosse um activista dos direitos humanos. Coimbra: Almedina.

Savater, F. (1992). La humanidad en cuestión. En: G. Vattimo (Ed.), La secularización de la filosofia: hermenéutica y posmodernidad (pp. 259-273). Barcelona: Gedisa.

Vattimo, G. (Ed.). (1992). La secularización de la filosofia: hermenéutica y posmodernidad. (Trads. C. Cattroppi \& M. N. Mizgraji). Barcelona: Gedisa. 